\title{
THE CONSUMPTION OF CHAOS: FROM THE CHARM OF CHAOS TO THE TEDIUM OF ORDER - THE CASE OF CHRISTCHURCH, NEW ZEALAND BEFORE AND AFTER THE CENTRAL CITY POST-EARTHQUAKE REBUILD
}

\author{
JOHN MCDONAGH, JACKY BOWRING \& HARVEY PERKINS \\ Lincoln University and University of Auckland, New Zealand
}

\begin{abstract}
Prior to the devastating 2010 and 2011 earthquakes, parts of the CBD of Christchurch, New Zealand were undergoing revitalisation incorporating aspects of adaptive reuse and gentrification. Such areas were often characterised by a variety of bars, restaurants, and retail outlets of an "alternative" or "bohemian" style. These early 20th century buildings also exhibited relatively low rents and a somewhat chaotic and loosely planned property development approach by small scale developers. Almost all of these buildings were demolished following the earthquakes and a cordon placed around the CBD for several years. A paper presented at the ERES conference in 2013 presented preliminary results, from observation of post-earthquake public meetings and interviews with displaced CBD retailers. This paper highlighted a strongly held fear that the rebuild of the central city, then about to begin, would result in a very different style and cost structure from that which previously existed. As a result, permanent exclusion from the $\mathrm{CBD}$ of the types of businesses that previously characterised the successfully revitalised areas would occur. Five years further on, new CBD retail and office buildings have been constructed, but large areas of land between them remain vacant and the new buildings completed are often having difficulty attracting tenants. This paper reports on the further development of this long-term Christchurch case study and examines if the earlier predictions of the displaced retailers are coming true, in that a new $\mathrm{CBD}$ that largely mimics a suburban mall in style and tenancy mix, inherently loses some of its competitive advantage?
\end{abstract}

Keywords: revitalisation, retail, CBD, style, chaos, variety, differentiation, earthquake, Christchurch, rebuild.

\section{INTRODUCTION}

Christchurch is a city of approximately 400,000 people on the east coast of the South Island of New Zealand. As with many cities, retailing in the central business district of Christchurch suffered since the 1970s, as competition from suburban shopping malls intensified. Over the last thirty years the commercial centre of Christchurch developed an entertainment and office focus, but retained a concentration of retail uses somewhat differentiated from the usual suburban mall offering [1], [2]. Some of the more eclectic businesses were concentrated in the south-east quadrant of the city, in an area of previously under-utilised and decaying semi industrial buildings known as Lichfield Lanes. This area had been identified in the mid-1990s as having unique architectural character and heritage values and, by 2010 revitalisation was gathering pace and encouraged by the wider community.

\section{THE RESEARCH PROCESS}

Leading up to the devastating earthquakes of 2010 and 2011 research was underway into factors important in making the revitalisation of the Lichfield Lanes area of the CBD a success. Unfortunately, the Lichfield Lanes area fell victim to both direct earthquake damage and the indirect impact of central city cordons, de-population and over-enthusiastic demolition post-earthquake. 


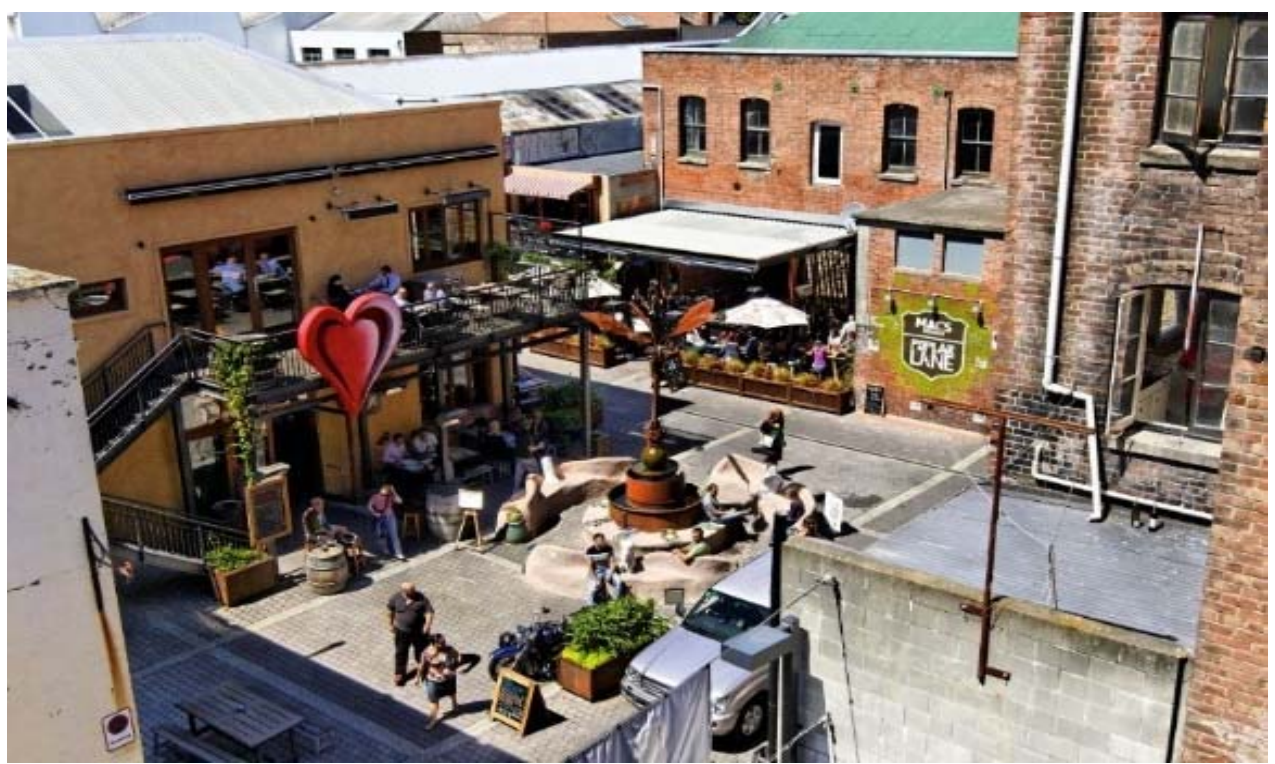

Figure 1: Lichfield Lanes area pre-earthquakes. (Source: Mr Sloth Flickr 2009 and http://thetwistedhopbrewery.co.nz/assets/Uploads/Poplar-lane 0663DxOraw2 .jpg.)

There followed prolonged political wrangling over the CBD rebuild, which was led by the Canterbury Earthquake Recovery Authority [CERA]. This research into CBD revitalisation was interrupted as a consequence, and did not fully resume until 2013, by which time it had necessarily taken a different direction.

This research was exploratory in nature as the Lichfield Lanes situation was unique, and still evolving. It was also moving from empirical observation in a case study situation towards tentative theory, so questions were approached inductively rather than deductively. Social constructionism offered an appropriate research framework and its naturalistic research method involved an iterative process of exploration and inspection for content and relations of all types of data available [3]. By listening carefully and analytically to the different actors in a social setting until "saturation" of concepts occurs, the researcher can identify common threads of actor interpretation. Results obtained in these ways can then be the basis for new theory to be tested and verified in subsequent research.

For the second part of the research, conducted in 2013 after the earthquakes and during the demolition and rebuilding process interviews with business owners in the Lichfield Lanes area were the key source of data. The knowledge gained supplemented that held by the authors as result of them all being long standing residents and analysts of the city. This introduced the potential for bias, which was recognised and managed. All business tenants willing to take part were interviewed and this represented nearly all of the business owners in the Lichfield Lanes area $(n=24)$. The timing and circumstances of the interviews reduced potential conflicts of interest as by the time of the interviews, the Lanes area had been destroyed and none of the respondents still had business interests there. The result was surprisingly candid and detailed revelations from the participants. 
The interviews were carried out on a semi-structured basis, involving open ended starter questions to get respondents to use their own words to explain the situation giving rise to the revitalisation pre-earthquakes. Expansion of responses was occasionally necessary, but very little prompting was used with interviewees all keen to give their interpretation. Interviews were digitally recorded, transcribed verbatim, then loaded into the NVivo software package to facilitate coding into nodes. Initially 34 nodes were identified, subsequently refined to 13 major themes. The objective of this process was to generate possible explanations and examine relationships rather than test hypotheses.

\section{THE RESEARCH QUESTION FOR THIS PAPER}

In the process of carrying out a broader investigation into inner city revitalisation, a compelling theme emerged from the business owners interviewed during 2013. Their perception then was that the Lichfield Lanes area prior to the earthquakes was unique in its combination of physical, social and economic characteristics, and, particularly suited to their businesses, in terms of style, and rental affordability. At the time of the interviews the CBD was still cordoned off with post-earthquake demolition continuing. The physical rebuild was yet to start, but interviewees had already concluded, from plans announced by the Canterbury Earthquake Recovery Authority (CERA), that the style and costs of the rebuilt central city would be incompatible with their businesses.

This paper looks back from five years on in the rebuild process (and eight years since the first Christchurch earthquakes) to examine if the fears expressed by these business owners in 2013 have eventuated. That is, that the combination of characteristics that were starting to give the revitalised parts of the CBD a competitive advantage over suburban malls have been lost. The key research question is, "In what ways have the rebuild processes for post-quake central Christchurch transformed the Lichfield Lanes area from a diverse and "grungy" urban character to more generic mall-like urban fabric?

\section{THE INTERVIEW OUTCOMES AND KEY THEMES}

A number of different themes were identified by all interviewees as being very important to central city revitalisation and many of these also frequently emerge in the revitalisation research literature. These themes include historic architecture, human scale, mixed uses, affordable rents, flexible development processes, non-monetary rewards, including feelings of community, all adding up to differentiation from the suburban mall experience. These themes are outlined below, as are the fears expressed by interviewees that the anticipated style of the rebuilt Christchurch CBD will lacking these important features. The interviewees have been given pseudonyms, as one of the ethics protocols for the research was to ensure anonymity.

The paper concludes with a summary of how the rebuild has actually played out to date in comparison to the interviewee's predictions. Historic architecture

The previous history, and the character and variety this gave to the Lichfield Lanes area was expressed as an attraction by almost all interviewees. Below are typical responses from Kate and George respectively:

But I really was drawn to the area purely because it's an old part of Christchurch with a lot of history. I love those sort of warehouse buildings and how multipurpose they could be.

We certainly wanted to try and get an outlet in that lane area, that old warehouse, old Christchurch area...so we were looking at whatever was available. 
This reflects the findings of Zukin [4], Ley [5], [6], Florida [7], Lloyd [8] and many other authors, who found that a certain group of people [sometimes termed the creative classes] are attracted to inner city historic areas which they see as authentic, exciting and different from the suburban mainstream.

4.2 Human scale, hidden, narrow lanes, edgy atmosphere

The narrowness and intimacy of the lanes, in contrast to the wide and traffic dominated streets nearby and more typical of Christchurch, was also an attractive factor as expressed by Bob:

Being tucked down a back street away from fast moving traffic so we thought it had potential for an outdoor seating area, it sounds crazy now but we thought people would kind of discover the area, you know, if they went down a back street they would think this is kinda cool.

A common observation was that the lanes were "hidden" and while initially a weakness it later became a strength, allowing the area to be "discovered" by customers. This was seen as a positive experience, promoting user loyalty and giving customers an element of surprise then exclusivity - being "in the know", fashionable and discerning as expressed by Ivy:

Yeah, you walk along the shops and there is a sense of discovering something and I remember feeling really proud talking about my business and people would say, where's that? and I say, it's [in the Lanes area],

This architectural style and in particular the intimate and varied indoor and outdoor areas generated, have been identified as important by authors such as Moe and Wilkie [9], Dane [10], [11] and others. This also reflects Jackson [12] who, along with many other authors, such as Jacobs [13], Gehl [14], and Whyte [15], talk about the narrow street as a public space blending domestic and public life - where interaction takes place. The street is no longer just a utility, but its small scale encourages random interaction. Jackson saw cities tending towards returning to a medieval scale with a rejection of the squares, parks and boulevards of the 19th and 20th century. This also ties in with the New Urbanism movement who promote the somewhat chaotic arrangement and mixed uses of old European cities as being more conducive to human interaction than the grand designs and zoning that have dominated in more recent times.

This attractiveness of old European cities was reflected in interviewee's comments as follows:

Alan:

... but going down [the] alleys inspired by bricks etc. European look. The old brick and the European look of the area, I guess, (was what) attracted us in the early stages.

George:

And the sort of intimacy with the lanes. We've seen a bit of that in Europe really.

Owen:

If you think about it a lot of people take an aeroplane to go to Europe and they go to the Amalfi coast and they go to these places... and the say ahh how beautiful it is you see how.... well... what happened in those environments actually, was variety was allowed. And so how character came up - because variety was allowed, so when they come back and land back in NZ, why do we have to think differently? 


\subsection{Mixed uses}

Interviewees frequently commented on the particular style and mix of tenancies as being significantly different from those offered in a suburban mall reflecting the work of Hernandez [16]. In particular, descriptions such as funky, edgy or eclectic were often used, which resonate with the findings of Florida [7] and other New Urbanist writers. Many urban researchers have commented on this importance of establishing a unique identity for a commercial area in order to change negative perceptions and differentiate the area from shopping malls, for example Dane [10], [11], Smith et al. [17], Suchman [18], Waxman [19], Gratz and Mintz [20], Toups and Carr [21], Seidman [22] among others. This was clearly evident in the Lichfield Lanes area pre-earthquakes and followed the findings of many of the above authors in being associated with historic buildings, key landmarks, specialized retail niches and ethnic composition.

Owen thought a variety of small owner-occupied businesses was especially important for success:

... the first thing was a vibe, there was a vibrancy, a vibrancy was made because there was variety of use. There was variety of businesses, they were small businesses.... when it was again its variety, variety, gives so much to a city life. I mean when everything starts being the same...

\section{As did Ivy:}

And you knew that there was a lovely mix of stores because the rents were... Relatively small spaces, relatively affordable rents, so I think it attracted a lot of people like myself who were independent business owners. They were the types of stores that you don't see in the mall you don't see in what's even now become like the Restart. It's not the highend thing, it's more, people who're having a go and sometimes had quite interesting services or products that they're offering and you know there was just a lovely mix that seemed to work really well.

\subsection{Affordable rents}

Although the physical aspects and variety mentioned above were attractive, the fundamental economic factor of rent was critical. This reflects Smith [23], [24] with his "rent gap" being exploited by these "pioneer" businesses. Similarly, Porter's [25], [26] ideas regarding the competitive advantage of CBD's, derived from infrastructure, density and local demand are relevant. The quotes below from Mike, Neil and Ivy respectively, illustrate how important low rents were in getting the Lichfield Lanes area established.

... they all survived because the rents were cheap...

... Oh, hugely important yeah, yep really important cheap rents

... Well for me, for us going in as a brand-new business that wasn't important, that was crucial.

It was not only the rent levels but also the small areas available, short lease durations and the flexibility to adapt and grow on a "do-it-yourself" basis that attracted new businesses to the area. However, it also became increasingly clear that these businesses were not just about making money - there were other non-monetary benefits of importance. 


\subsection{Satificing and owner operators}

Somewhat paradoxically, it became clear from the research that many business owners were not concerned about making lots of money. They did need to make a living, but their total return from their investment and efforts was much more complex. This dividend incorporated aspects such as relishing the challenge of building an enterprise, the self-determination benefits of being self-employed, the value of the physical environment, the enjoyment of social interaction with other nearby businesses, customers and the wider public, and pride in the business owner's achievements and the contributions they made to the city. These mixed means of achieving satisfaction fit neatly into the satisficing concept established by Simon [27], which has been identified by as being particularly applicable to small businesses in a New Zealand context by Smale [28], [29], Rowarth and Parsons [30], Whyte [31] among others. The comment below is an expressive but largely typical interviewee response.

Ivy:

... kind of for me the shop too was always more than a business. It was about having, you know, a satisfying, happy experience and it's hard to replicate that. It was just a magical little spot and I did feel like we were characters in a book or something. I haven't probably said this stuff to other people but.... like, I felt sometimes like I could be, I could leave my life behind and go drive up there. And I'd be sweeping outside and I'd feel like a character in the book Chocolat, where she has a chocolate shop.

\subsection{Community}

Also, part of the experience of being a business in the Lanes area was a feeling of community. This was raised by almost all interviewees. Linda's account below being typical.

But yeah, community, our customers were amazing. They were so sick of being in malls and thought that what we were doing was amazing and you create relationships with them... but also, we treated our customers so special. It wasn't just the kind of service that you would get anywhere. On a Friday we would give them a glass of wine!

Ivy had a similar comment:

So, I think that mixture of cafes and bars and retail shops just all worked really well together and it really just very quickly seemed like a real community of people ......it was. And so, there were people I saw more often than my family, more often than close friends, and you've seen them every day or most days for the last couple of years......

When asked "what do you think was making it work down there?" Neil immediately responded:

One, the community thing yeah.... but everything - it is such a community.

\subsection{Chaos and difference from a mall}

As mentioned in the accounts above, the differentiation of the Lanes area retail experience from that in the large suburban malls that encircle Christchurch was one of the key recurring themes throughout the interviews. A complex combination of the physical, economic and social factors mentioned previously plus an unplanned and organic development process all contributed to what many saw as a "European" style to the Lichfield Lanes area. Interviewees 
wanted to incorporate the organic atmosphere of street life and small scale, personal service orientated businesses they felt was typical of old European cities.

Dave:

And if I could put my finger on what was really special about Poplar Lanes, compared to the other ones (areas), it was they (were) all (business) owner operators.... and I think you get a character from an owner operator which you don't get from absentee owner(s). One person's...or a group of people's passions and they're there all the time and they are the face of this and they.... you just can't beat an owner operator for personality that puts into a tenancy.

Kate:

Umm, I know for myself that was the biggest part that attracted me to the area... was that I could create what I wanted, not what somebody else dictates to me, and so that's exciting for me .... very organic, yeah. And I loved that.

Alan:

I think it was very much evolving... Seen as a cluster of some businesses... just an idea rather than reality. Just evolved... there was a concept but very loose and just grew organically... I think that is ultimately what made it work. That was certainly an attraction for us, it wasn't regimented, a formulation at all.

Dave again, this time on the appeal of chaos:

... I like the constraints of old areas... buildings having to fit around each other. Area grows organically. Just don't get that with new buildings where everything is nicely designed... I think dysfunction and chaos is underrated.

This issue of a different atmosphere for revitalised areas, in part generated by lifestyle and ethnic differences from the mainstream, is a recurring theme in the literature, for example Grogan and Proscio [32], Machlup [33], Drucker [34], Florida [7], Hernandez [16]. A related theme is that those attracted to revitalised CBD's typically react adversely to being controlled and manipulated, (Dutton [35], Short [36], Lightner [37], Frank [38], Zukin [39], Minton [40] and many others).

This was a stark contrast to the US style suburban malls dominating retailing in Christchurch and a strong concern was expressed by interviewees that the centralised top down and corporate approach emerging in the CERA plans would result in the latter for a rebuilt $\mathrm{CBD}$. The quotes below are typical:

Ivy:

...they were the types of stores that you don't see in the malls, you don't see in what's even now become like the Restart.

Owen:

... we didn't like the shopping centre type of setup. It was pedestrian life: and it was pedestrian life what really appealed.

Gemma:

... unlike the Strip which holds absolutely no interest to us at all.... it's soulless...

Alan: 
... CERA announced compulsory purchase of properties.... No future at all for us there. Could foresee rents would be beyond what we could afford because it would all be new buildings and landlords would need return on these and they also would not fit in with our image or our affordability either.

Mike:

Yeah, I can't see how a new city where everything is being built from scratch and the rentals are going to be so high - it's not going to have the same personality. It only attracts a very, very minimal clientele.... too contrived. And look at the buildings being built now and they are all very glass and concrete, 2-3 stories high and that has their limitations as to the businesses they will attract.

\section{THE CURRENT SITUATION}

The situation in the CBD of Christchurch five years on from 2013 is largely as predicted by the interviewees. Almost none of the Victorian and Edwardian era buildings that were a feature of Lichfield Lanes and much of the rest of central Christchurch remain. Nor do the small, eclectic, funky owner operated businesses that previously inhabited them. The city is now characterised by corporate style new build office buildings with ground floor retail shops, the latter largely mimicking the style of shopping found in suburban malls - see Fig. 2.

The central city re-build started in earnest during 2014, led by the private sector, rather than the much-lauded government led "Anchor Projects". Most of the latter, apart from a bus exchange, playground and justice precinct, are yet to start or have only recently commenced.

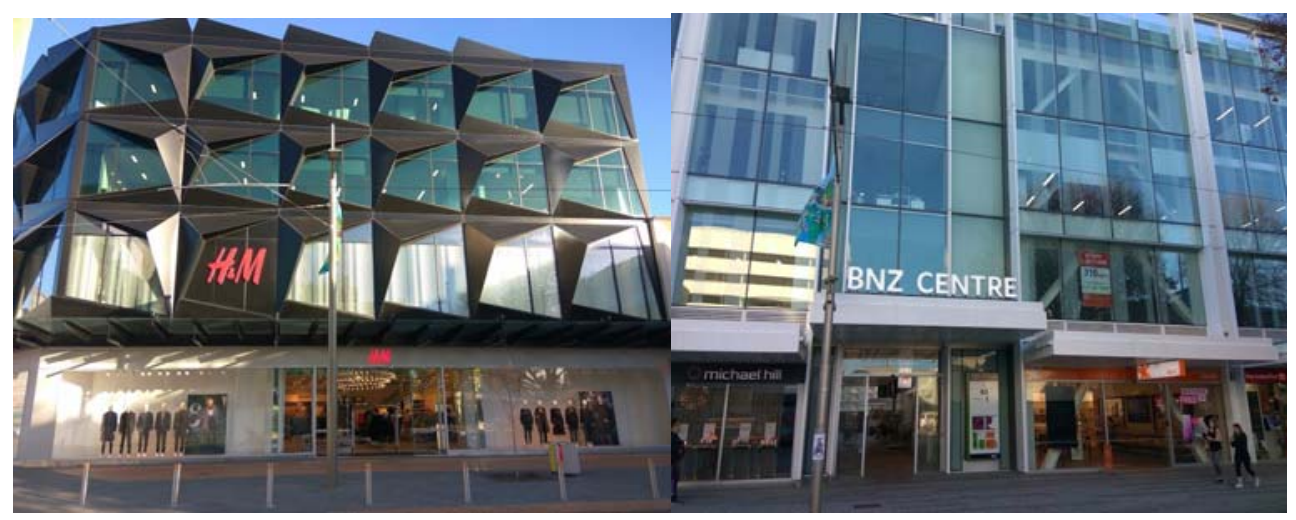

Figure 2: Typical new retail/office buildings Christchurch CBD. (Source: author.)

Many of the private sector developments also faced obstacles, not least of which was dealing with the government established Canterbury Earthquake Recovery Authority (CERA). This organisation was charged with planning and then facilitating the rebuild of the $\mathrm{CBD}$ and rejected an ambitious, community engagement led, Christchurch City Council plan and replaced it with a consultant developed plan developed over 100 days. This plan stipulated the consolidation of the CBD into a smaller footprint, surrounded by a "frame" of 
recreational, residential and cultural uses. While this "100-day plan" garnered some support, the implementation was problematical. Under the plan the core of the CBD required buildings of at least four levels covering a minimum land area of $7500 \mathrm{~m}^{2}$. This meant that to take part in the rebuild, many of the smaller and medium sized land owners were forced to amalgamate their holdings with adjacent larger owners to achieve the minimum size for an approved development. The development expertise, financing and tenant commitment required for such a large-scale development also presented challenges for what were, usually, passive investors in relatively small, individually owned and low rent buildings. The alternative was to simply sell their land holdings to adjacent owners or CERA, who also had compulsory acquisition powers.

CERA announced that large scale international rebuild expertise and finance would be attracted by their staff from offshore, but this never eventuated. Instead the rebuild was led by a few wealthy individual land owners who had more than a simply financial interest in the future of the CBD. Some of these central city owners benefited from sometimes very large (in the order of $\$ N Z 100 \mathrm{~m}$ and more) replacement cost insurance policies and chose, or were required by the policies, to reinvest these funds in rebuilt premises in the CBD. Other owners fell victim to failed insurance companies, inadequate pay-outs, lengthy legal battles, development process frustration and simply banked the insurance proceeds or chose to invest them in a different location.

Even those who initially committed to rebuild in the core CBD faced major hurdles, including lengthy delays in access to their premises, changing development plans and other problems in dealing with the rebuild authorities. This included all designs for buildings having to be considered by an Urban Design Panel and approved by the City Council. The result was some owners eventually elected to develop new buildings just outside the CERA controlled area. The result was a doughnut effect, the opposite of the CBD consolidation planned. This still lingers today, with some 20 hectares of vacant land in the CBD with no firm plans for development, much of it being currently used for gravel covered temporary parking lots. Some core CBD developments did eventually proceed and have recently opened for business, but as feared by the interviewees, these are almost universally corporate and shopping mall in style as shown in Fig. 2. In some cases, this style was forced upon the owners by the need to obtain finance and the consequent insistence by the lenders on longer term leases to "bankable" corporate tenants - often the same retailers dominating competing suburban malls.

As well as being uncomfortable with the anticipated mall style of a rebuilt CBD, unaffordable rents were also frequently raised by interviewees as an expected barrier to their future participation in the city. Prior to the earthquakes, the majority of small CBD retailers were paying annual rent in the range of $\$ 200-\$ 300 \mathrm{~m}^{2}$. In just off prime locations rents in the vicinity of $\$ 450 \mathrm{~m}^{2}$ were typical. There were higher rents of up to $\$ 1000 \mathrm{~m}^{2}$ paid in a small number of prime locations, and this space was also usually occupied by corporate style tenants pre-2011.

Post-earthquake, increased building strength requirements have driven up construction costs so that rents on prime, ground floor, new build, retail space are now in the vicinity of $\$ 1000-\$ 1200 \mathrm{~m}^{2}$ per annum. At this level there are questions as to whether this is an economic return on development costs and also, if even corporate retailers, can afford these rents given current foot fall.

While the prime retail area rent increases post-earthquake of up to $20 \%$ are problematic, even more important is the impact of increased rents in off prime and secondary retail locations. These rents are now in the range $\$ 600-\$ 800 \mathrm{~m}^{2}-$ more than double typical equivalent rents pre-earthquake, while retailer tenants cope with significantly less foot traffic 
passing the doors. It was businesses similar to those interviewed from the Lichfield Lanes area that previously occupied this secondary space and added the edgy, quirky and bohemian experience that differentiated the CBD from suburban malls. While there has been limited uptake of this newly built fringe retail space by hospitality operator's post-earthquake, some of these have failed after a relatively short time and others are reported as struggling. A recent front-page newspaper headline was "Hospitality carnage on the cards for Christchurch".

\section{CONCLUSION AND IMPLICATIONS FOR A COMPETITIVE CBD IN THE FUTURE}

The interviewees from the Lichfield Lanes area in this research project, at a very early stage, accurately predicted the corporate style and expensive rents of the post-earthquake rebuild of the Christchurch CBD, and also that their businesses would not be part of it. They strongly valued the unique combination of physical, social and economic factors that characterised their location pre-earthquakes, which they felt particularly suited their businesses, in terms of style, and rental affordability, as well as their psychological needs for freedom and selfdetermination.

While post-earthquake there was expressed enthusiasm by planners and other authorities to build on the central city revitalisation successes that were emerging pre-earthquake, the processes used in the post-earthquake rebuild were incompatible with retaining the style and variety of quirky retail businesses that are critical to successful CBD differentiation. These process problems included; long delays, limited site access, compulsory land amalgamation, prescriptive planning, design restrictions, insurance and finance issues, high land and construction costs, plus lack of development expertise. The result is the rebuilt Christchurch CBD now largely mimics and therefore directly competes with well-established and professionally run suburban malls, that shoppers usually have to drive right past on their way into the central city.

If revitalised $\mathrm{CBD}$ areas are to maximise the few competitive advantages they have over suburban shopping centres there is a need for processes to be more responsive to the needs of individual property owners and their owner operator tenants. than undertaking the more monolithic and corporate approach as has happened in Christchurch.

While entertainment and office uses are now slowly returning to the $\mathrm{CBD}$, this is only replicating the sub-optimal situation generally existing pre-earthquakes, but with even less variety of retail uses and architectural style. In these circumstances it remains to be seen who will ultimately win the battle for retail spending and associated vitality, in Christchurch postearthquakes, but it appears to be unlikely it will be the CBD.

\section{REFERENCES}

[1] McDonagh, J., Demand/supply analysis for the tourist hotel market. New Zealand Valuers Journal, pp. 16-26, 1997.

[2] Wilson, J., Contextual Historical Overview of Christchurch City. Report. Christchurch: Christchurch City Council, 2005.

[3] Blumer, H., Symbolic Interactionism: Perspective and Method, 1969.

[4] Zukin, S., Loft Living: Culture and Capital in Urban Change, Rutgers University Press; 1989.

[5] Ley, D., Alternative Explanations for inner-city gentrification: a Canadian assessment. Annals of the Association of American Geographers, 76, pp. 521-535, 1986.

[6] Ley, D., Gentrification and the politics of the new middle class. Environment and Planning D: Society and Space, 12(1), pp. 53-74, 1994.

[7] Florida, R., The Rise of the Creative Class, Basic Books, 2002. 
[8] Lloyd, R., Neo-Bohemia: art and neighborhood redevelopment in Chicago. Journal of Urban Affairs, 24(5), pp. 517-532, 2002.

[9] Moe, R. \& Wilkie, C., Changing Places: Rebuilding Community in the Age of Sprawl, Henry Holt \& Company, 1997.

[10] Dane, S.G., New directions for urban main streets, National Main Street Center, National Trust for Historic Preservation, 1988.

[11] Dane, S.G., Main Street success stories. 1997.

[12] Jackson, J.B., The American public space. The Public Interest, 74, p. 52, 1984.

[13] Jacobs, J., The Death and Life of Great American Cities, Vintage; 1961.

[14] Gehl, J., Life Between Buildings, using public space, Island Press, 2011.

[15] Whyte, W.H., The Social Life of Small Urban Spaces, 1980.

[16] Hernandez, M.M., Impact of commercial development on inner city revitalization, An Analysis of Projects in Boston, 2001.

[17] Smith, K., Joncas, K. \& Parrish, B., Revitalizing downtown: National Main Street Center, National Trust for Historic Preservation, 1996.

[18] Suchman, D.R., Revitalizing low-income neighborhoods: Recommendations from ULI Advisory Services Panels, Urban Land Inst., 1994.

[19] Waxman, A.A.P., Utilizing economic theories of retail to revitalize inner-city neighborhood business districts: the case of Uphams Corner Main Street, Massachusetts Institute of Technology, 1999.

[20] Gratz, R.B. \& Mintz, N., Cities Back from the Edge: New Life for Downtown, John Wiley \& Sons, 2000.

[21] Toups, C. \& Carr, J.H., Reimaging distressed communities: a strategy to reverse decline and attract investors. Building Blocks, 1(1), 2000.

[22] Seidman, K.F., Wanted: Solutions for America Final Research Report, Boston Main Streets Program, 2001.

[23] Smith, N., Gentrification and the rent-gap. Annals of the Association of American Geographers, 77(3), pp. 462-465, 1987;

[24] Smith, N., The New Urban Frontier: Gentrification and the Revanchist City, New York: Routledge, 1996.

[25] Porter, M.E., The competitive advantage of the inner city. Harvard Business Review, 73(3), pp. 55-71, 1995.

[26] Porter, M.E., New strategies for inner-city economic development. Economic Development Quarterly. 11(1), pp. 11-27, 1997.

[27] Simon, H.A., Rational choice and the structure of the environment. Psychological review, 63(2), p. 129, 1956.

[28] Smale, T., Playing to Our Strengths: Creating Value for Kiwi Firms. In: Enterprise NZTa, editor. Wellington: NZ. Government, 2009.

[29] Smale, T., Why understanding national culture is necessary in order to understand innovation performance. New Zealand Science Review, 70(3), pp. 62-67, 2013.

[30] Rowarth, J. \& Parsons, A., Enabling innovation. New Zealand Science Review, 68, pp. 19-23, 2011.

[31] Whyte, R., (ed), Constraints to innovation in New Zealand: an exploratory study Small Enterprise Association of Australia and New Zealand. 28th Annual SEAANZ Conference Proceedings, Melbourne, 2015.

[32] Grogan, P.S. \& Proscio, T., Comeback Cities: A Blueprint for Urban Neighborhood Revival, Basic Books, 2000.

[33] Machlup, F., The production and distribution of knowledge in the United States: Princeton University Press, 1962. 
866 Sustainable Development and Planning X

[34] Drucker, P.F., Post-Capitalist Society, Routledge, 1994.

[35] Dutton, P., Leeds calling: the influence of london on the gentrification of regional cities. Urban Studies, 40(12), pp. 2557-2572, 2003.

[36] Short. J.R., Yuppies, yuffies and the new urban order. Transactions of the Institute of British Geographers, pp. 173-188, 1989

[37] Lightner, B.C., Design review: a critical evaluation. Cities, 9(4), pp. 280-287, 1992

[38] Frank, T., The Conquest of Cool: Business Culture, Counterculture, and the Rise of Hip Consumerism, University of Chicago Press, 1998.

[39] Zukin, S., How to Create a Culture Capital: Reflections on Urban Markets and Places, pp. 258-265, 2001.

[40] Minton, A., Northern Soul: Culture. Creativity and quality of place in Newcastle and Gateshead, Published by DEMOS \& RICS. 2003. 